\title{
INFLUÊNCIA DA TEMPERATURA DE REFRIGERAÇÃO SOBRE AS CARACTERÍSTICAS QUÍMICAS DO MAMÃO CV. "GOLDEN"1
}

\author{
Robson Ferreira de ALMEIDA², Meire Lelis Leal MARTINS'², Eder Dutra de RESENDE ${ }^{2, *}$, \\ Letícia VITORAZI ${ }^{2}$, Lanamar de Almeida CARLOS ${ }^{2}$, Luciana Konda de Azevedo PINTO²
}

\begin{abstract}
RESUMO
Neste trabalho, foi investigado o efeito da temperatura de refrigeração sobre as características químicas do mamão cv "Golden". O estudo foi conduzido tanto na metade externa como na metade interna do mesocarpo dos frutos. Os frutos, apresentando de $10 \%$ a $15 \%$ de cor amarela e peso médio de $500 \mathrm{~g}$, foram selecionados na linha de embalagem da Caliman Agrícola S. A. (Linhares - ES), após sofrerem tratamentos térmicos e químicos. Eles foram embalados em filmes plásticos Xtend ${ }^{\mathrm{TM}}$-PP7 e estocados a $6{ }^{\circ} \mathrm{C}$ e $13{ }^{\circ} \mathrm{C}$ (85-95\% UR) por 30 dias. Os resultados mostraram que, para ambas as temperaturas de estocagem, a metade externa do mesocarpo dos frutos apresentou valores maiores de acidez titulável que a metade interna. Por outro lado, foi encontrado que o conteúdo de sólidos solúveis totais (SST) foi maior na metade interna do mesocarpo. Isto foi observado até o décimo oitavo dia de armazenamento. A partir deste período, apenas os frutos mantidos a $6{ }^{\circ} \mathrm{C}$, mantiveram teores maiores de SST na sua metade interna. Em relação ao conteúdo de matéria seca, a metade interna do mesocarpo dos frutos estocados a $13{ }^{\circ} \mathrm{C}$ por 18 dias, também apresentou valores maiores que a metade externa.

Palavras-chave: mamão, estocagem refrigerada, maturação, composição química.
\end{abstract}

\section{SUMMARY}

INFLUENCE OF THE REFRIGERATING TEMPERATURE ON THE CHEMICAL CHARACTERISTICS OF THE PAPAYA FRUITS CV "GOLDEN". In this work was investigated the effect of the refrigerating temperature on the chemical characteristics of the papaya fruit cv "Golden". The study was carried out as in the outer as inner mesocarp halves of the fruits. The fruits presenting $10 \%$ to $15 \%$ fruit skin yellowing and medium weight of $500 \mathrm{~g}$ were sorted in the packaging line of the Caliman Agrícola S.A (Linhares-ES), after suffering chemical and heat treatments. They were wrapped in Xtend ${ }^{\mathrm{TM}}$-PP7 plastic films and stored at $6{ }^{\circ} \mathrm{C}$ and $13{ }^{\circ} \mathrm{C}(85-95 \% \mathrm{RH})$ for 30 days. According to the results found to both storage temperatures, the outer mesocarp halves of the fruits presented higher values of titratable acidity than the inner mesocarp halves. On the other hand, it was found that the contents of total soluble solids (SST) were higher in the inner mesocarp halves. This was observed until the eighteen days of storage. From this period, only the fruits maintained at $6{ }^{\circ} \mathrm{C}$ continued with the higher values of SST in the inner mesocarp halves. Regarding to the dry matter contents, the inner mesocarp halves of the fruits, stored at $13{ }^{\circ} \mathrm{C}$ for eighteen days, also presented higher values in the inner mesocarp halves. Keywords: papaya, refrigerated storage, ripening, chemical composition.

\section{1 - INTRODUÇÃO}

O Brasil é o terceiro maior produtor mundial de frutas, totalizando, em 2002, aproximadamente 38 milhões de toneladas, destacando-se na produção de banana, laranja, coco e mamão [13]. Além disso, o País é o maior produtor mundial de mamão com aproximadamente $26 \%$ do total de 5,6 milhões de toneladas. Em 2004, as exportações brasileiras deste fruto foram da ordem de 26,7 mil toneladas, representando aproximadamente $1,8 \%$ do total produzido em 2002, revelando o grande potencial de incremento do comércio internacional da produção. Os principais mercados são a Holanda, EUA, Portugal, Reino Unido e Espanha [4]. O restante da produção é comercializado no mercado interno, que apresenta um consumo per capita de $57 \mathrm{~kg} /$ ano, sendo considerado de grande potencial de expansão comercial

\footnotetext{
${ }^{1}$ Recebido para publicação em 19/5/2005. Aceito para publicação em 6/7/2006 (001531)

${ }^{2}$ Laboratório de Tecnologia de Alimentos (LTA),

Centro de Ciências e Tecnologias Agropecuárias (CCTA),

Universidade Estadual do Norte Fluminense (UENF),

Av. Alberto Lamego, 2000, Parque Califórnia, CEP 28013-600,

Campos dos Goytacazes (RJ),

E-mail:eresende@uenf.br

* A quem a correspondência deve ser enviada
}

quando se compara com a Espanha, que apresenta um consumo de $120 \mathrm{~kg} /$ ano [13].

A comercialização interna do mamão é feita em condições inadequadas de estocagem, transporte e manipulação pós-colheita, provocando perdas significativas da produção. Estas perdas podem variar de $20 \%$ até $75 \%$ da produção comercializada [17].

O armazenamento refrigerado é um dos métodos mais efetivos e práticos utilizados para o prolongamento da vida útil de frutos "in natura". Sob tal condição, o metabolismo do fruto, a respiração e o processo de amadurecimento são retardados. A velocidade e a intensidade com que essas alterações ocorrem são dependentes das características genotípicas, das condições edafoclimáticas de cultivo, condições de colheita e de armazenamento [14].

A temperatura mínima para o armazenamento do mamão é determinada pela sua susceptibilidade à injúria pelo frio. Temperaturas compreendidas entre 9 e $12{ }^{\circ} \mathrm{C}$ são geralmente as mais utilizadas para o seu armazenamento [8]. Durante a estocagem do mamão sob refrigeração, várias alterações metabólicas são observadas, como mudanças na taxa respiratória [1], conteúdos de clorofila e carotenóides na casca $[1,2]$, firmeza da polpa [8, 2] e perda de massa. 
Os frutos de mamoeiro cultivar "Golden" tiveram uma grande participação no volume de exportação do mamão nos últimos anos. Conseqüentemente, torna-se importante avaliar os parâmetros de qualidade destes frutos, quando estocados em condições de refrigeração.

Neste contexto, este trabalho teve como objetivo avaliar o efeito de duas temperaturas de refrigeração, $6{ }^{\circ} \mathrm{C}$ e $13{ }^{\circ} \mathrm{C}$, sobre as características químicas de frutos de mamoeiro cv "Golden", em duas posições radiais do mesocarpo.

\section{2 - MATERIAL E MÉTODOS}

Frutos de mamoeiro (Carica papaya L.) cv "Golden" provenientes de um mesmo talhão foram selecionados na linha de operações da Caliman Agrícola S. A. (Linhares - ES), em Novembro/02, apresentando $15 \%$ de coloração amarela na casca e peso médio de 500 g. Os frutos sofreram tratamento térmico, banho de fungicida e resfriamento em câmara fria a $10{ }^{\circ} \mathrm{C}$. Posteriormente, foram transportados sob refrigeração a $10^{\circ} \mathrm{C}$ até o Laboratório de Tecnologia de alimentos (LTA/CCTA) da Universidade Estadual do Norte Fluminense. Os experimentos foram realizados $24 \mathrm{~h}$ após a colheita dos frutos.

Os frutos foram embalados individualmente em filmes copolímeros laminados Xtend ${ }^{\mathrm{TM}}$-PP7 (StePac L.A.), com dimensões de $20 \times 30 \mathrm{~cm}$. Posteriormente, foram armazenados a $6{ }^{\circ} \mathrm{C}$ e a $13{ }^{\circ} \mathrm{C}$ (85\%-95\% UR) em incubadoras dotadas de sistema de ventilação forçada (BOD), marca Marconi, modelo MA 415, por 30 dias. Em intervalos de seis dias, 6 frutos foram retirados aleatoriamente das incubadoras e tiveram suas extremidades descartadas. Posteriormente, na região equatorial destes frutos, foram separadas as metades interna e externa do mesocarpo, onde foram conduzidas as análises químicas.

A coloração da casca foi determinada utilizando o colorímetro de Hunter modelo MiniScan XE Plus com padrão de iluminação D65/10. Os resultados foram avaliados a partir dos perfis de cromaticidade no espectro da luz visível. A leitura de cor foi feita na região equatorial do fruto, em quatro pontos eqüidistantes.

As análises químicas foram realizadas após a homogeneização das amostras em multi-processador (Arno). O conteúdo de Matéria Seca (MS) foi obtido a partir de $5 \mathrm{~g}$ da amostra e normalizado para $100 \mathrm{~g}$ da polpa, mantida em estufa a $105{ }^{\circ} \mathrm{C}$ por $48 \mathrm{~h}$, conforme metodologia da AOAC [3].

O conteúdo de Sólidos Solúveis Totais (SST) foi determinado utilizando-se um refratômetro digital ATAGO modelo PR 201, com medidas em graus Brix. O material foi homogeneizado com um multiprocessador da marca Arno e filtrado em malha de pano morim.

A Acidez Titulável (AT) foi determinada em \% de ácido cítrico, após homogeneização e diluição da amostra (5 g) em 150 mL de água destilada e titulação potenciométrica com $\mathrm{NaOH} 0,01 \mathrm{~N}$, monitorando o ponto de viragem do indicador em pH 8,1, conforme o método da AOAC [3]. O
pH foi medido com pHmetro WTW Modelo 330, após imersão direta do eletrodo na solução da amostra.

O experimento foi conduzido em um Delineamento Inteiramente Casualizado (DIC) no esquema fatorial 6 (tempos) $\times 2$ (temperaturas) $\times 2$ (regiões do mesocarpo), com seis repetições. Os dados foram submetidos à análise de variância e as médias comparadas pelo Teste de Tukey, ao nível de $5 \%$ de probabilidade.

\section{3 - RESULTADOS E DISCUSSÃO}

Os perfis de cromaticidade da casca dos frutos armazenados por 30 dias nas temperaturas de $6{ }^{\circ} \mathrm{C}$ e $13{ }^{\circ} \mathrm{C}$ estão mostrados na Figura 1 . Os frutos estocados a $13{ }^{\circ} \mathrm{C}$ (Figura 1a) amadureceram ao final de 30 dias de armazenamento, conforme indicado pelo deslocamento do pico máximo do índice de reflectância da casca da região do espectro de reflexão do início da mudança de cor verde (560 nm) para o amarelo (600 nm). Entretanto, aos 30 dias de estocagem, quando os frutos apresentavam amarelecimento completo da casca, foi observada uma redução no índice de reflectância, provavelmente devido à incidência de fungos que ocorreu neste período.

Os frutos estocados a $6{ }^{\circ} \mathrm{C}$ tiveram a sua maturação inibida (Figura $1 b$ ). Além disso, a injúria pelo frio que foi observada nestes frutos entre o sexto e o décimo segundo dia de estocagem alteraram os índices de reflectância da
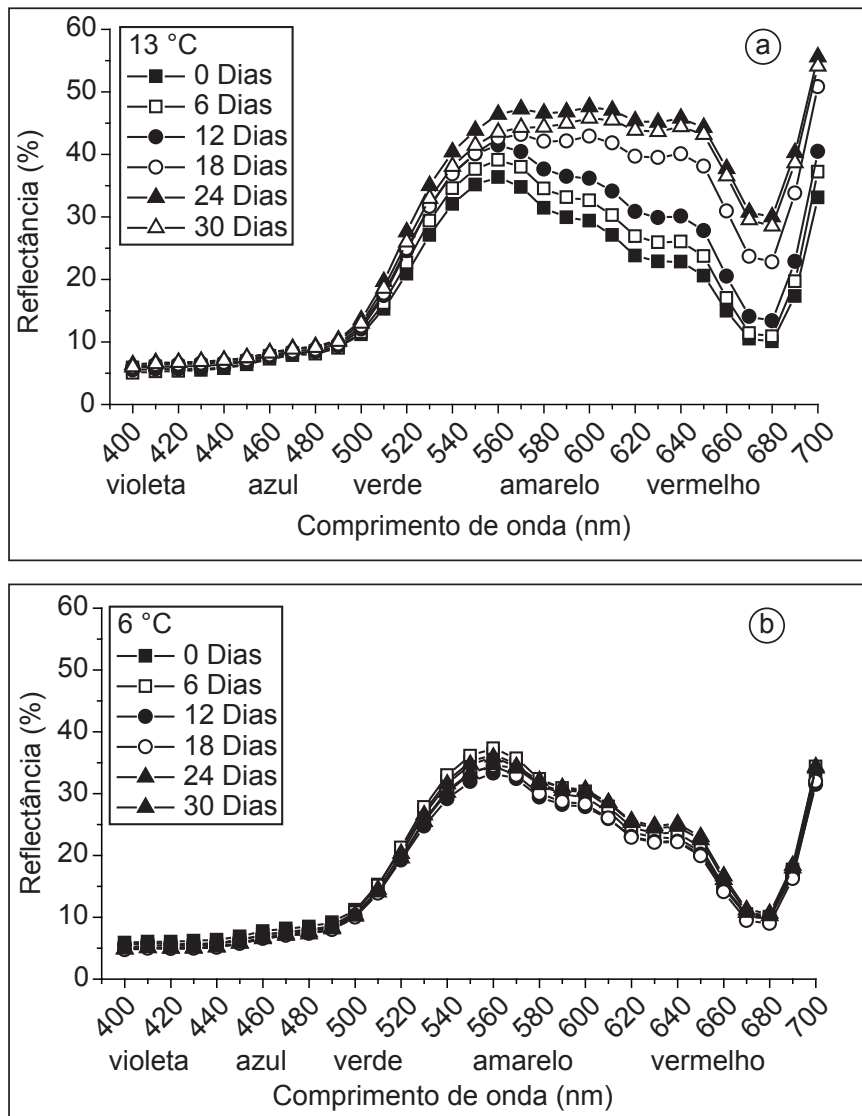

FIGURA 1 - Perfis de cromaticidade da casca de mamões (Carica papaya L.) cv. "Golden" armazenados a $13{ }^{\circ} \mathrm{C}$ (a) e $6{ }^{\circ} \mathrm{C}(\mathrm{b})$ durante um período de 30 dias. 
casca. Provavelmente, isto ocorreu em virtude da inibição, tanto da hidrólise da clorofila como da síntese de carotenóides [12].

A variação da acidez titulável nas partes internas e externas dos frutos armazenados a $6{ }^{\circ} \mathrm{C}$ e a $13{ }^{\circ} \mathrm{C}$, durante 30 dias, está mostrada na Tabela 1 . Os resultados revelaram que a metade externa do mesocarpo apresentou uma acidez maior do que a metade interna, ao longo de todo o processo de maturação a $13{ }^{\circ} \mathrm{C}$. Aos 30 dias de estocagem, a parte externa dos frutos alcançou valores médios de acidez titulável $46 \%$ maiores que a parte interna. Neste mesmo período, os frutos estocados a $6{ }^{\circ} \mathrm{C}$ permaneceram verdes e apresentaram uma proporção $36 \%$ maior de acidez na metade externa do mesocarpo, quando comparada com a metade interna da polpa. Segundo DRAETTA et al. [10], o aumento da acidez, principalmente na parte superior da polpa de frutos de mamão ao longo do seu amadurecimento, está possivelmente vinculado com a formação de ácido galacturônico, proveniente da hidrólise da pectina pela pectinametilesterase.

Os frutos armazenados a $13{ }^{\circ} \mathrm{C}$ apresentaram um aumento significativo da acidez na parte externa do mesocarpo aos seis dias de estocagem. Este aumento da acidez pode ser devido aos ácidos galacturônicos liberados durante a hidrólise de componentes da parede celular, responsáveis pela firmeza dos tecidos [18]. A partir do sexto dia de armazenamento e até o décimo oitavo dia, houve um declínio dos valores da acidez titulável de $0,195 \%$ para $0,145 \%$ na parte externa da polpa dos frutos. Segundo DRAETTA et al. [10], o processo de amadurecimento do mamão é sustentado pelo consumo dos ácidos orgânicos, uma vez que o fruto não apresenta reservas de amido.

Um novo incremento da acidez na metade externa do mesocarpo ocorreu entre o décimo oitavo e o vigésimo quarto dia de estocagem do mamão a $13{ }^{\circ} \mathrm{C}$. Este incremento é devido ao aumento da atividade metabólica característica do pico climatérico do mamão, que levaria à síntese de ácidos orgânicos [16]. Estes resultados são similares aos encontrados por CÂMARA, DÍEZ \& TORIJA [5], que observaram uma elevação da acidez durante o amadurecimento do mamão armazenado à temperatura de $10{ }^{\circ} \mathrm{C}$. Segundo Chan et al. [6], o ácido cítrico e o málico estão presentes em quantidades aproximadamente iguais nos frutos do mamoeiro. O ácido $\alpha$-cetoglutárico, em quantidades dez vezes menores que os dois. O ácido ascórbico responde por $18 \%$ da acidez titulável, enquanto que o ácido cítrico, málico e $\alpha$-cetoglutárico juntos respondem por, aproximadamente, $67 \%$. Os teores de ácidos voláteis responderam por $8 \%$, enquanto que os ácidos galacturônico, tartárico, péctico, totalizam $7 \%$ da acidez titulável.

A redução da temperatura de armazenamento $\left(6^{\circ} \mathrm{C}\right)$ retardou o processo de amadurecimento, uma vez que a elevação inicial da acidez na metade externa do mesocarpo ocorreu somente no décimo segundo dia de armazenamento $(0,170 \%)$, ocorrendo um atraso de 6 dias em relação ao valor observado para os frutos estocados a $13{ }^{\circ} \mathrm{C}$ (Tabela 1 ). Posteriormente, os frutos apresentaram uma redução de acidez até o final da estocagem, indicando que o acúmulo final de acidez, observado nos frutos estocados a $13{ }^{\circ} \mathrm{C}$, foi inibido pelo abaixamento de temperatura.

De uma maneira geral, o aumento da acidez está relacionado com a redução dos valores de $\mathrm{pH}$. As medidas de $\mathrm{pH}$ da polpa, entretanto, não identificaram diferenças significativas entre as duas metades do mesocarpo dos frutos estocados a $13{ }^{\circ} \mathrm{C} \mathrm{e} 6^{\circ} \mathrm{C}$ ( Tabela 2 ). Estes resultados concordam com aqueles obtidos por LAZAN et al. [15], que verificaram discrepâncias entre a acidez titulável e as medidas de $\mathrm{pH}$ da polpa nas duas regiões do mesocarpo de mamões “Backcross Solo”. Os ácidos orgânicos da polpa do mamão são considerados como ácidos fracos e, portanto, apresentam baixa dissociação. Isso, possivelmente, explica a não ocorrência de diferenças significativas nas medidas de $\mathrm{pH}$ entre as duas metades do mesocarpo.

TABELA 1 - Acidez titulável (\% ácido cítrico) da parte externa (E) e interna (I) do mesocarpo de mamões (Carica papaya L.) "Golden" armazenado a $6{ }^{\circ} \mathrm{C} \mathrm{e} 13{ }^{\circ} \mathrm{C}$, em diferentes tempos de armazenamento.

\begin{tabular}{ccllllll}
\hline T $\left({ }^{\circ} \mathbf{C}\right)$ & Parte & \multicolumn{5}{c}{ Tempo de armazenamento (dias) } \\
\cline { 3 - 7 } & & \multicolumn{1}{c}{$\mathbf{0}$} & $\mathbf{6}$ & $\mathbf{1 2}$ & $\mathbf{1 8}$ & $\mathbf{2 4}$ & $\mathbf{3 0}$ \\
\hline 6 & $\mathrm{E}$ & $0,148 \mathrm{Aab}$ & $0,160 \mathrm{Aab}$ & $0,170 \mathrm{Aa}$ & $0,158 \mathrm{Aab}$ & $0,138 \mathrm{Ab}$ & $0,141 \mathrm{Ab}$ \\
& $\mathrm{I}$ & $0,086 \mathrm{Ba}$ & $0,096 \mathrm{Bab}$ & $0,100 \mathrm{Bab}$ & $0,101 \mathrm{Bab}$ & $0,080 \mathrm{Bc}$ & $0,090 \mathrm{Bab}$ \\
13 & $\mathrm{E}$ & $0,148 \mathrm{Abc}$ & $0,195 \mathrm{Aa}$ & $0,165 \mathrm{Aabc}$ & $0,145 \mathrm{Ac}$ & $0,178 \mathrm{Aab}$ & $0,150 \mathrm{Abc}$ \\
& $\mathrm{I}$ & $0,086 \mathrm{Ba}$ & $0,108 \mathrm{Ba}$ & $0,095 \mathrm{Ba}$ & $0,081 \mathrm{Ba}$ & $0,090 \mathrm{Ba}$ & $0,081 \mathrm{Ba}$ \\
\hline
\end{tabular}

As médias seguidas de uma mesma letra maiúscula na coluna e minúscula na linha, em cada temperatura, não diferem entre si pelo teste de Tuckey ao nível de $5 \%$.

TABELA 2 - Valores de pH da metade externa (E) e interna (I) do mesocarpo de mamões (Carica papaya L.) "Golden" armazenados a $6{ }^{\circ} \mathrm{C}$ e $13{ }^{\circ} \mathrm{C}$, em diferentes tempos de armazenamento.

\begin{tabular}{|c|c|c|c|c|c|c|c|}
\hline \multirow[t]{2}{*}{$\mathrm{T}\left({ }^{\circ} \mathrm{C}\right)$} & \multirow[t]{2}{*}{ Parte } & \multicolumn{6}{|c|}{ Tempo de armazenamento (dias) } \\
\hline & & 0 & 6 & 12 & 18 & 24 & 30 \\
\hline \multirow[t]{2}{*}{6} & $E$ & $5,583 \mathrm{Ab}$ & $5,666 \mathrm{Ab}$ & $5,700 \mathrm{Ab}$ & $5,700 \mathrm{Ab}$ & $5,750 \mathrm{Ab}$ & $6,216 \mathrm{Aa}$ \\
\hline & I & $5,466 \mathrm{Ac}$ & $5,566 \mathrm{Abc}$ & $5,683 \mathrm{Abc}$ & $5,466 \mathrm{Ac}$ & $5,716 \mathrm{Ab}$ & $6,033 \mathrm{Aa}$ \\
\hline \multirow[t]{2}{*}{13} & E & $5,583 \mathrm{Ac}$ & $5,503 \mathrm{Ac}$ & $5,450 \mathrm{Ac}$ & $5,966 \mathrm{Aa}$ & $5,450 \mathrm{Ac}$ & $5,783 \mathrm{Abc}$ \\
\hline & I & $5,466 \mathrm{Ac}$ & $5,450 \mathrm{Abc}$ & $5,333 A c$ & $5,933 \mathrm{Aa}$ & $5,350 \mathrm{Ac}$ & 5,716 Aac \\
\hline
\end{tabular}

As médias seguidas de uma mesma letra maiúscula na coluna e minúscula na linha, em cada temperatura, não diferem entre si pelo teste de Tuckey ao nível de $5 \%$. 
Destaca-se, contudo, que ocorreram variações significativas de $\mathrm{pH}$ ao longo do tempo de armazenamento (Tabela 2). Nota-se que os maiores valores de $\mathrm{pH}$ na metade externa do mesocarpo dos frutos estocados a $13{ }^{\circ} \mathrm{C}$ ocorreram aos 18 dias de estocagem, em concordâncias com os menores valores de acidez titulável (Tabela 1 ). No caso dos frutos estocados a $6{ }^{\circ} \mathrm{C}$, os maiores valores de $\mathrm{pH}$ ocorreram no final do armazenamento em concordância com os menores índices de acidez na metade externa do mesocarpo. Essas variações de $\mathrm{pH}$ ao longo do armazenamento podem ser atribuídas à degradação inicial e a posterior síntese de ácidos orgânicos com diferentes potenciais de dissociação iônica.

O conteúdo de sólidos solúveis totais (SST) nas duas partes do mesocarpo dos frutos estocados a $6{ }^{\circ} \mathrm{C}$ e a $13{ }^{\circ} \mathrm{C}$ está mostrado na Tabela 3 . Os frutos estocados a $13{ }^{\circ} \mathrm{C}$ apresentaram um pequeno incremento do conteúdo de SST na parte externa do mesocarpo, entre o início $\left(8,79{ }^{\circ} \mathrm{Brix}\right)$ e o final da estocagem ( $\left.10,12{ }^{\circ} \mathrm{Brix}\right)$. A metade interna do mesocarpo não acumulou SST, mas apresentou valores mais elevados do que a parte externa até o décimo oitavo dia de estocagem e atingiu uma média de $11,08{ }^{\circ} \mathrm{Brix}$ ao final da estocagem. Esses resultados confirmam os relatos de que há uma atividade metabólica mais intensa na porção interna do mesocarpo [16].

Os frutos estocados a $6{ }^{\circ} \mathrm{C}$ não acumularam SST na metade externa do mesocarpo e mantiveram concentrações mais baixas do que a parte interna ao longo e todo o período de estocagem. Segundo CHITARRA \& CHITARRA [9], as baixas temperaturas de estocagem têm a capacidade de retardar a atividade metabólica, reduzindo a síntese e degradação dos polissacarídeos e carboidratos.

De acordo com CHAN, HIBBARD \& GOO [7], os açúcares solúveis são acumulados, em sua maior parte, quando o fruto ainda está ligado à planta, provavelmente, em função da fotossíntese. No início do desenvolvimento dos frutos de mamoeiro, a glicose é o açúcar predominante, já, em estágios mais avançados, a sacarose torna-se o açúcar encontrado em maior concentração, atingindo níveis mais elevados que a frutose e a glicose. De acordo com os resultados encontrados neste estudo, parece haver, em pequena proporção, síntese de açúcares no período pós-colheita, já que os teores de sólidos solúveis totais aumentaram na parte externa do mesocarpo no decorrer do amadurecimento.

GÓMEZ, LAJOLO \& CORDENUNSI [11] relataram que os teores de glicose e frutose, em frutos de mamoeiro estocados a $18{ }^{\circ} \mathrm{C}$ por 10 dias, foram constantes, exceto ao final do amadurecimento, quando aumentaram. Os autores atribuíram esse aumento à atividade das invertases, que são enzimas relacionadas ao metabolismo da sacarose.

O conteúdo de matéria seca nos frutos estocados a $13{ }^{\circ} \mathrm{C}$, foi maior na metade interna do mesocarpo até o décimo oitavo dia de estocagem, em conformidade com o conteúdo de SST que também foi maior nesta região. Um comportamento semelhante foi verificado para os frutos estocados a $6{ }^{\circ} \mathrm{C}$ (Tabela 4$)$.

Destaca-se que o conteúdo de matéria seca da polpa dos frutos estocados a $13{ }^{\circ} \mathrm{C}$ aumentou ao final da estocagem. Isto se deve, provavelmente, à síntese de compostos orgânicos, que ocorre durante o período do climatério [16].

\section{4 - CONCLUSÕES}

Os mamões "Golden" estocados a $13{ }^{\circ} \mathrm{C}$ e a $6{ }^{\circ} \mathrm{C}$ apresentaram um gradiente de composição química entre as metades interna e externa do mesocarpo, mostrando que a separação destas regiões proporciona uma diferenciação de qualidade de polpa dos frutos ou de produtos minimamente processados.

O abaixamento da temperatura de estocagem minimizou as modificações químicas durante o armazenamento. Na tem-

TABELA 3 - Variação do teor de sólidos solúveis totais ( ${ }^{\circ}$ Brix) nas metades externa (E) e interna (I) do mesocarpo dos mamões (Carica papaya L.) "Golden" armazenados a $6{ }^{\circ} \mathrm{C}$ e $13{ }^{\circ} \mathrm{C}$ durante um período de 30 dias.

\begin{tabular}{|c|c|c|c|c|c|c|c|}
\hline \multirow[t]{2}{*}{$\mathrm{T}\left({ }^{\circ} \mathrm{C}\right)$} & \multirow[t]{2}{*}{ Parte } & \multicolumn{6}{|c|}{ Tempo de armazenamento (dias) } \\
\hline & & 0 & 6 & 12 & 18 & 24 & 30 \\
\hline \multirow[t]{2}{*}{6} & $E$ & $8,785 \mathrm{Ba}$ & $9,066 \mathrm{Ba}$ & $8,673 \mathrm{Ba}$ & $9,166 \mathrm{Ba}$ & $8,933 \mathrm{Ba}$ & $9,433 \mathrm{Ba}$ \\
\hline & 1 & $10,855 \mathrm{Aa}$ & $11,330 \mathrm{Aa}$ & $10,700 \mathrm{Aa}$ & $11,450 \mathrm{Aa}$ & $11,448 \mathrm{Aa}$ & $11,330 \mathrm{Aa}$ \\
\hline \multirow[t]{2}{*}{13} & E & $8,785 \mathrm{Bb}$ & $9,250 \mathrm{Bab}$ & $9,755 \mathrm{Bab}$ & 9,393Bab & $9,655 \mathrm{Aab}$ & $10,116 \mathrm{Aa}$ \\
\hline & I & $10,855 \mathrm{Aa}$ & $11,333 \mathrm{Aa}$ & $11,066 \mathrm{Aa}$ & $10,755 \mathrm{Aa}$ & $10,500 \mathrm{Aa}$ & $11,083 \mathrm{Aa}$ \\
\hline
\end{tabular}

As médias seguidas de uma mesma letra maiúscula na coluna e minúscula na linha, em cada temperatura, não diferem entre si pelo teste de Tuckey ao nível de 5\%.

TABELA 4 - Conteúdo de matéria seca (\%) nas metades externa (E) e interna (I) do mesocarpo dos mamões (Carica papaya L.) "Golden" armazenados a $6{ }^{\circ} \mathrm{C}$ e $13{ }^{\circ} \mathrm{C}$, em diferentes tempos de armazenamento.

\begin{tabular}{|c|c|c|c|c|c|c|c|}
\hline \multirow[t]{2}{*}{$\mathrm{T}\left({ }^{\circ} \mathrm{C}\right)$} & \multirow[t]{2}{*}{ Parte } & \multicolumn{6}{|c|}{ Tempo de armazenamento (dias) } \\
\hline & & 0 & 6 & 12 & 18 & 24 & 30 \\
\hline \multirow[t]{2}{*}{6} & $E$ & $13,756 \mathrm{Bbc}$ & $13,471 \mathrm{Bc}$ & $13,456 \mathrm{Bc}$ & $13,446 \mathrm{Ac}$ & $15,395 \mathrm{Aa}$ & $14,510 \mathrm{Bb}$ \\
\hline & 1 & $15,418 \mathrm{Ab}$ & $15,391 \mathrm{Ab}$ & $15,140 \mathrm{Ab}$ & $14,098 \mathrm{Ac}$ & $16,485 \mathrm{Aa}$ & $16,468 \mathrm{Aa}$ \\
\hline \multirow[t]{2}{*}{13} & $E$ & $13,756 \mathrm{Bbc}$ & $14,648 \mathrm{Bb}$ & $14,478 \mathrm{Bb}$ & $13,366 \mathrm{Bc}$ & $14,563 \mathrm{Ab}$ & $16,913 \mathrm{Aa}$ \\
\hline & I & $15,418 \mathrm{Abc}$ & $16,438 \mathrm{Ab}$ & $15,665 \mathrm{Ab}$ & $14,641 \mathrm{Ac}$ & $15,568 \mathrm{Abc}$ & $17,80 \mathrm{Aa}$ \\
\hline
\end{tabular}

As médias seguidas de uma mesma letra maiúscula na coluna e minúscula na linha, em cada temperatura, não diferem entre si pelo teste de Tuckey ao nível de $5 \%$. 
peratura de $13{ }^{\circ} \mathrm{C}$, os frutos amadureceram e apresentaram um incremento de acidez na parte externa do mesocarpo ao final de 30 dias de estocagem, ao contrário dos frutos mantidos a $6{ }^{\circ} \mathrm{C}$ que permaneceram verdes e não mostraram este incremento final de acidez.

Os frutos estocados a $13{ }^{\circ} \mathrm{C}$ mostraram um incremento de SST na metade externa do mesocarpo, alcançando uma igualdade de conteúdo de SST com a parte interna a partir do décimo oitavo dia de armazenamento. Os frutos mantidos a $6{ }^{\circ} \mathrm{C}$ não mostraram evolução no conteúdo de SST da metade externa do mesocarpo, permanecendo com uma concentração mais elevada de SST na metade interna do mesocarpo ao longo de todo o armazenamento. O mesmo comportamento foi identificado para o conteúdo de matéria seca.

\section{5 - REFERÊNCIAS BIBLIOGRÁFICAS}

[1] ABOU AZIZ, A. B., EL-NABAAWY, S. M. ZAKI, H. A. Effect of different temperatures on the storage of papaya fruits and respirational activity during storage. HortScinece, v. 3, n. 3, p. 173-177, 1975.

[2] AN, J.; PAULL, R. E. Storage temperature and ethylene influence on ripening of papaya fruit. J. Amer. Soc. Hort. Sci., v. 115, n. 6, p. 949-953, 1990.

[3] AOAC -. Association of official analytical chemistry Oficial methods of analyses of the Association of Official Analytical Chemistry. $11^{\circ}$ Edição. Washington, 1998.

[4] BRAPEX - Associação Brasileira dos Exportadores de Papaya. http://www.brapex.net/ Acesso em: 10/04/05. 2005

[5] CÂMARA, M. M.; DÍEZ, C.; TORIJA, M. E. Changes during ripening of papaya fruit in different storage systems. Food Chemistry, v. 46, p. 81-84, 1993.

[6] CHAN JR, H. T.; CHANG, T. S. K.; STANFFORD, A. E.; BREKKER, J. E. Nonvolatile acids of papaya. Journal of Agricultural \& Food Chemistry, v. 19, n. 2, p. 263-265, 1971.

[7] CHAN JR, H. T.; HIBBARD, K. L.; GOO, T. Sugar composition of papayas during fruit development. HortScience, v. 14, n. 3, p. 140-141, 1979.

[8] CHEN, N. M.; PAULL, R. E. Developmente and prevention of chilling injury in papaya fruit. Journal America Society HortScience, v. 114, n. 4, p. 639-643, 1986.
[9] CHITARRA, M. I. F; CHITARRA,A. B. Pós-colheita de frutos e hortaliças: fisiologia e manuseio. Lavras. FAEPE, ESAL, 293p, 1990.

[10] DRAETTA, I. dos S., SHIMOKAMI, M., YOKOMIZO, Y., FUJITA, J. T., MENEZES, H. C., BLEINORITH, E. W. Transformações bioquímicas do mamão (Carica papaya L.) durante a maturação. Coletânea do Instituto de Tecnologia de Alimentos, Campinas, v. 6, n. 2, p. 395-408, 1975.

[11] GÓMEZ, M.; LAJOLO, F.; CORDENUNSI, B. Evolution of solubles sugars during ripening of papaya fruit and its relation to sweet tast. Journal of Food Science, v. 67, n. 1, p. 442-447, 2002.

[12] HULME, A.C. The biochemistry of fruits and their products. Londres. Academic Press, v. 1, 620p, 1970.

[13] IBRAF - Instituto Brasileiro de Frutas. http://www.ibraf. org.br/ Acesso em: 11/04/05. 2005

[14] KADER, A. A.; ZAGORY, D.; KERBEL, E. L. Modified atmosphere packaging of fruits and vegetables. Critical reviews in Food Science and Nutrition, Boca Raton, v. 28, n. 1, p. 1-30, 1989.

[15] LAZAN, H., MOHD. ALI, Z. LIANG, K. S., YEE, K. L. Polygalacturonase activity and variation in ripening of papaya fruit with tissue depth and heat treatment. Physiologia Plantarum, v. 77, p. 93-98, 1989.

[16] PAULL, R. E.; CHEN, N. J. Postharvest variation in cell wall-degradin enzymes of papaya (Carica papaya L.) during fruit ripening. Plant physiology, v. 72, p. 382-385, 1983.

[17] PAULL, R. E.; NISHIJIMA, W.; Reyes, M.; CAVALETTO, C. Postharvest handling and losses during marketing of papaya (Carica papaya L.). Postharvest Biology and Technology, v.11, p.165-179, 1997.

[18] PAULL, R. E.; GROSS, K.; QIU, Y. Changes in papaya cell walls during fruit ripening. Postharvest Biology and Technology, v.16, p. 79-89, 1999.

\section{6 - AGRADECIMENTOS}

Os autores agradecem à FAPERJ, à FINEP e ao MCT/ CNPq pelo auxílio financeiro e à Caliman Agrícola S. A. pela parceria de pesquisa no Projeto Frutimamão. 